\title{
Membangun Branding Image Kepulauan Riau Sebagai Destinasi Wisata Nasional
}

\author{
Jamhur Poti $^{1}$, Agus Hendrayady ${ }^{2}$ \\ ${ }^{1,2}$ Program Studi Ilmu Administrasi Negara, Fakultas Ilmu Sosial dan Ilmu Politik \\ Universitas Maritim Raja Ali Haji \\ jamhur_poti2000@yahoo.com, agushendrayady05081973@gmail.com
}

\begin{abstract}
ABSTRAK
Branding Image bukan hanya sekadar merk dan bukan sekedar logo, brand adalah segalanya bagi sebuah produk. Bagi dunia wisata, brand juga sama maknanya, namun brand destinasi harus lahir dari filosofi dan nilai-nilai sebuah destinasi serta keunggulan yang unik. Branding Image akan memberi kekuatan kepada destinasi yang direpresentasi bila brand mendapat proses branding yang baik dan konsisten. Akhir-akhir ini eforia wisata Indonesia kadang irrasional dan hanya mengandalkan data sesaat, padahal posisi-posisi Indonesia masih jauh dari yang diharapkan. Sebagai brand destinasi, maka brand harus dibangun berdasarkan realitas sosial yang benar di dalam tergambarkan realitas sosial, yaitu culture, personality, name, logo dan symbol Penelitian ini mencoba mengangkat kajian realitas sosial brand destinasi dengan metode narasi, mencoba membandingkannya dengan kondisi Wonderful Kepri, Wonderful Riau Island sampai Welcome to Batam.. Kepulauan Riau memilik banyak potensi sebagai destinasi wisata nasional maupun internasional, hanya saja belum memiliki daya tarik tersendiri untuk dijual. Untuk menunjang dan memiliki daya saing Kepulauan Riau sebagai destinasi wisata perlu ada sebuah brand yang menjadi Citra sebagai destinasi wisata. Suatu Branding yang dikombinasikan dari unsur dan budaya daerah di Kepulauan Riau. Kesimpulan bahwa Kepulauan Riau memerlukan suatu brand atau citra sebagai destinasi wisata nsional agar dapat memberikan pesan bagi wisatawan agar tertarik untuk mengunjungi Kepulauan Riau sebagai salah satu alternatif dari 10 besar sebagai destinasi wisata nasional.
\end{abstract}

Kata Kunci: Branding Image Kepulauan Riau, Destinasi Wisata.

\begin{abstract}
Branding Image is not about a brand and logo, but everything aboutr a product. For the tourism world, branding is the same, but a destination brand should be created from the viewpoint of philosophy, destination values and unique advantages. Branding Image will give power to the represented destination if the brand gets a good and consistent branding process. Lately, Indonesia's tourism euphoria is sometimes irrational and only relies on momentary data, even though the present situation is a far cry from the anticipated. Therefore, a destination brand, should be dependent on true social reality, such as culture, personality, name, logo and symbol. This study examines the social reality of destination brands using narrative methods vis-a-vis the conditions of Wonderful Kepri, Riau Island and Welcome to Batam Monument. Riau Islands has a lot of potential as national and international tourist destinations, but does not yet have its own attractiveness for sale. To support and have competitiveness, Riau Islands needs to have a brand image of tourist destination; which is a combination of regional elements and culture in Riau Islands. Therefore, it can be concluded that the Riau Islands as a national tourism destination needs a brand image that projects a message which arouses the interest of tourists to visit the Riau Islands as an alternative to the top 10 national tourist destinations.
\end{abstract}

Keywords: Branding Image of Riau Islands, Tourism Destinations. 


\section{PENDAHULUAN}

Letak geografis Kepuluan Riau yang strategis antara Laut Cina Selatan dan Selat Malaka dengan kekayaan alam yang sangat potensial. Kepulauan Riau yang terdiri dari $96 \%$ perairann, laut dan $4 \%$ daratan dimungkinkan untuk menjadi salah satu pusat pertumbuhan ekonomi bagi Republik Indonesia dimasa depan. Selain sebagai wilayah Kepulauan juga berpotensi menjadi destinasi wisata bahari dikarenakan letak Kepulauan Riau yang berhadapan langsung dengan negara tetangga Singapura dan Malaysia. Disamping itu Kepulauan Riau juga menjadi konektivitas antara satu daerah dengan daerah lainnya. Selain jalur laut beberapa wilayah perlu dihubungkan dengan bandar udara.

Beberapa di antaranya sudah dirintis pembangunannya meskipun saat ini belum maksimal dalam memberikan pelayanan transportasi kepada masyarakat yang berada di luar Kepulauan Riau. Gagasan untuk menjadikan Kepulauan Riau sebagai destinasi wisata Indonesia, harus didukung oleh kebijakan dan keputusan yang sungguh-sungguh. Dibutuhkan kebijakan- kebijakan jangka pendek, kemauan (good will) politik yang kuat dengan mengutamakan masa depan Indonesia yang lebih baik melalui potensi kemaritimannya. Menurut (Poti, 2016) ada beberapa alasan untuk menjadikan Kepulauan Riau sebagai destinasi wisata, antara lain;

Pertama, Kepulauan Riau sudah diberi anugerah potensi kelautan yang melimpah ruah. Bukan hanya potensi perikanan ratusan juta ton yang bisa ditangkap, biota laut yang kaya, juga kekayaan tambang gas dan minyak yang besar. Jika dalam konteks ekonomi kemaritiman, pertahanan dan ketahanan wilayah, adalah sektor yang sangat strategis dan niscaya, maka potensi kelautan dan pertambangan itu memerlukan benteng pertahanan dan keamanan, dan itu adalah benteng masuk ke Indonesia karena Kepulauan Riau adalah kawasan perbatasan terdepan dengan luas perairan dan garis pantai yang luar biasa panjangnya.

Kedua, Kepulauan Riau punya Batam, sebuah kawasan ekonomi yang sudah berkembang pesat, sudah menyerap triliunan dana pembangunan nasional, memiliki keistimewaan sebagai kawasan perdagangan dan pelabuhan bebas atau free trade zone (FTZ). Serta memiliki infrastruktur ekonomi kemaritiman yang cukup memadai. Batam sudah dianggap Singapura-nya Indonesia. Hongkong-nya Indonesia. Sebuah pelabuhan bebas yang sudah berkembang. Memiliki pelabuhan laut yang cukup. Punya industri kemaritiman yang terbesar di Indonesia, lebih 100 industri galangan kapal. Punya industri lepas pantai dan sudah memproduksi ratusan buah rig lepas pantai yang kini bertaburan di laut Cina Selatan. Lembaga keuangan dan dunia usaha yang sudah sangat maju, dan lain- lain. Ini kelebihan Batam dibandingkan dengan pusat-pusat pertumbuhan ekonomi maritim lainnya di Indonesia.

Ketiga, Kepulauan Riau, meskipun dengan kemampuan dana pembangunan terbatas dan kebijakan kemaritiman yang belum konsisten dan masih parsial, sudah menciptakan pusat-pusat pertumbuhan ekonomi berbasis maritim. Paling tidak ada tujuh daerah pertumbuhan ekonominya yang berbasis maritim, dan itu ada di kabupatennya, daerah-daerah kepulauan yang dalam masa reformasi dan era otonomi ini, tumbuh dan berkembang cukup pesat memanfaatkan potensi kemaritimannya.

Keempat; Kepulauan Riau bukan mustahil segera terwujud sebagai bagian dari visi 
Indonesia untuk menjadi poros maritim dunia. Keberadaan Batam sebagai salah satu pusat perkembangan ekonomi Indonesia yang selama ini cenderung diabaikan, harus dimanfaatkan maksimal. Baik sebagai pelabuhan maupun sebagai kawasan yang memiliki infrastruktur ekonomi secara bebas, sudah yang memadai. Di bidang wisata, Batam dan Bintan merupakan tujuan wisata utama Indonesia setelah Jakarta dan Bali. Batam dan Bintan sebagai primadona destinasi wisata nasional maupun manca negara sudah sangat berperan penting dan mengambil alih sebsgian peran Singapura dan Jakarta.

Provinsi Kepulauan Riau yang dikenal wisata baharinya, pemerintah pusat dan daerah telah berupaya meningkatkan akses infrastruktur yang dikelola secara berkelanjutan, sehingga bisa diakses secara menyeluruh oleh wisatawan domestik dan wisata mancanegara (Karlina \& Iskandar, 2017). Dalam konteks menjadikan Kepulauan Riau sebagai salah satu destinasi wisata Indonesia, maka Batam dan Bintan harus jadi pusat pengembangan dan pengendalian ekonomi kemaritimam dan wisata Kepulauan Riau dan kawasan sekitarnya. Batam dan Bintan harus berperan sebagai bandar tempat semua kekuatan dan keperluan ekonomi kemaritiman kawasan ini bermula, tersedia, dan dikembangkan.

Jika puluhan tahun lalu Singapura dan Hongkong menjadi kiblat ekonomi dan kemaritiman Indonesia, maka peran itu harus segera diambil alih. Batam dengan seluruh kawasan sekitarnya dapat menjadi pelopor wisata maritim atau bahari. Batam dengan segala keunggulanya sekarang, tidak boleh lagi dikelola dengan setengah hati, akan tetapi sudah harus dikelola dengan konsep yang terpadu. Harus jadi kekuatan yang menggerakkan dan memiliki daya tarik. Membangun potensi ekonomi baru, termasuk ekonomi maritim, baik perikanan, pelayaran, perdagangan, maupun industri, memang memerlukan keterlibatan dan campur tangan pemerintah.

Kebutuhan wisatawan untuk kegiatan pengalaman di berbagai bidang telah meningkat selama dekade terakhir; dengan mengadopsi perspektif branding terhadap kegiatan pasar. (Liang et al., 2020). Brand destinasi merupakan suatu masalah yang masih sangat baru, baik pada kajian wisata, pemasaran, komunikasi maupun kebijakan publik di suatu negara. Di berbagai negara, sektor wisata ini telah menjadi fenomena sosial dan ekonomi yang sangat menarik, di mana kajian komunikasi menjadi wilayah kajian yang sangat strategik ketika ditinjau dari fenomena tersebut (Bungin, 2015).

Salah satunya di kawasan ASEAN, Thailand dalam pengembangan wisatanya melalui branding yang paling baik dalam mengangkat perekonomian dengan pasar yang ada di negara tersebut (Kovathanakul, 2015). Banyak juga perusahaan-perusahaan memperkuat industri wisata dengan ikatan antar ke perusahaan pusat lain di jaringan yang diperluas (closeness centrality) cobrand dengan brand tujuan antara pemangku kepentingan melalui kerjasama yang resmi (Aarstad et al., 2015).

Perusahaan yang terlibat dalam wisata industri harus fokus pada menawarkan pengalaman interaktif bagi wisatawan untuk meningkatkan asosiasi merek dan memastikan proses operasi yang transparan selama tur untuk menekankan kualitas tinggi dari apa pun yang diproduksi, sehingga berkontribusi untuk meningkatkan brand wisata (Chow et al., 2017).

Masalah inti wisata terletak pada pemberdayaan dan pengembangan sumber daya alam adalah pemetaan terhadap potensi dan strategi pengembangan wisata belum dimaksimalkan 
sehingga perlu adanya konsep berkelanjutan serta pemberdayaan masyarakat kepulauan (Mahadiansar \& Aspariyana, 2020) maka dari itu peneliti penting adanya Branding Image sebagai upaya pengembangan destinasi wisata yang berkelanjutan dalam rangka promosi visi kelautan dan kemaritiman Indonesia yang pada gilirannya menarik lebih banyak investor, wisatawan, maupun mempertinggi nilai dan daya saing perdagangan dengan beberapa negara lainnya.

Jika menoleh ke belakang, Branding Image Indonesia lebih banyak mengangkat keragaman budaya, hayati dan alam, kini saatnya Indonesia perlu membangun branding image sesuai visi kelautan dan maritim yang hendak dicapai pemerintah. Slogan kampanye seperti Wonderful Indonesia, tidak secara tegas menghadirkan kekuatan potensi wisata Sehingga perlu diubah menjadi tagline yang menonjolkan keunggulan sektor kelautan dan maritim sebagai destinasi wisata yang dimiliki Indonesia. Tidak hanya menyentuh sektor wisata semata, melainkan juga perlu mencerminkan potensi alam dan industri kelautan secara luas.

Sehingga tidak hanya menarik wisatawan untuk berkunjung, melainkan juga mampu mengundang minat para investor untuk menanamkan investasinya pada sektor kelautan dan maritim di Indonesia. Namun sampai saat ini masih banyak wacana dalam melakukan branding di Indonesia, seperti Wonderful Indonesia" atau "remarkable Indonesia". Merek Kepualauan Riau masih belum dapat dikenal di Internasional, bahkan cenderung diabaikan, harus dimanfaatkan maksimal. baik sebagai destinasi wisata maupun sebagai kawasan yang memiliki infrastruktur ekonomi secara bebas dan sudah memadai.

Secara umum image dapat dideskripsikan dengan karakteristik-karakteristik tertentu seperti manusia, semakin positif deskripsi tersebut semakin kuat brand image dan semakin banyak kesempatan bagi pertumbuhan merek (Davis, 2002). Kemudian (Wilson \& Blumenthal, 2008) menjelaskan bahwa brand image adalah berupa gambaran total tentang bagaimana pemikiran khalayak terhadap brand anda, dan bagaimana brand anda dipersepsikan oleh orang-orang di sekitar anda.

(Straub \& Attner, 1994) definisi brand image yaitu "Brand is a name, symbol, design, or combination of them that identifies the goods or service of a company”. Menurut (Morgan et al., 2011) menjelaskan bhwa negara-negara juga harus menggunakan faktor-faktor lunak seperti lingkungan, orang-orang lokal yang ramah, budaya dan layanan rekreasi untuk membedakan penawaran serta memberikan tempat harus memberikan perhatian khusus bagi wisatawan dalam mengunjungi destinasi sebagai upaya pengembangan branding. Kemudian (Straub \& Attner, 1994) membagi brand menjadi tiga, yaitu:

a. Nama (brand name): bentuk kata, huruf, atau gabungan keduanya yang digunakan untuk memberikan ciri khas.

b. Tanda (brand mark): simbol atau desain yang digunakan untuk memberikan ciri dan membedakannya

c. Karakter (trade caracter) simbol yang menunjukan kualitas manusia

Brand dapat disebut merek. Brand dapat membantu penjual dan berkaitan dengan kepercayaan konsumen terhadap suatu produk dan layanan, yang diyakini tidak saja dapat memenuhi kebutuhan mereka tetapi dapat memberikan kepuasan yang lebih baik dan terjamin 
(Harrigan et al., 2017) (Santos \& Giraldi, 2017). Brand muncul ketika persaingan produk semakin tajam dan menyebabkan perlunya penguatan peran label untuk mengelompokkan produk dan layanan yang dimilik dalam satu kesatuan guna membedakan produk itu dengan produk bersaing.

Menurut (Kotler \& Armstrong, 2006) Branding itu tentang membawa sesuatu yang biasa dan meningkatkannya dengan cara-cara yang membuatnya menjadi lebih berharga dan bernilai. Ketika berbicara tentang brand sebagian orang akan segera ingat pada coca cola, aple, nokia, rinso dan mungkin aqua. Beberapa brand ini juga sering di kutip dalam bidang bisnis ke consumer. Bagi sebuah perusahaan brand mewakili aset yang kuat dan bertahan lama, pemicu nilai sebenarnya yang telah menaikkan kesuksesan perusahaan yang di harapkan dapat tercapai.

"Brand melayani tujuan umum yang persis sama dalam pasar seperti halnya pada consumer. Brand merupakan alat efektif untuk mengomunikasikan manfaat dan nilai suatu produk atau jasa. Brand merupakan jaminan kualitas, asal usul dan performa yang dengan demikian mening- katkan nilai yang dirasakan customer dan mengurangi resiko dalam keputusan membeli." (Kotler \& Armstrong, 2006, p. 4)

Lebih rinci Kotler menjelaskan, brand image adalah sebuah perangkat keyakinan, ide dan kesan yang dimiliki oleh seseorang terhadap suatu brand. Oleh sebab itu, sikap dan tindakan konsumen sangat ditentukan oleh brand image tersebut. Brand image merepresentasikan keseluruhan persepsi terhadap merek dan dibentuk dari informasi serta pengalaman terhadap merek itu dan perilaku konsumen eksternal dapat diprediksi di masa depan berdasarkan pengalaman terhadap brand (Matiza \& Slabbert, 2020).

Mereka juga menambahkan proses keputusan pembelian terdiri dari lima tahap yaitu tahap pengenalan kebutuhan, pencarian informasi, evaluasi alternatif, keputusan membeli, dan perilaku pasca. Adapun manfaat brand image yaitu:

1. Brand image dapat dilihat sebagai tujuan di dalam strategi pemasaran.

2. Brand image dapat dipakai sebagai suatu dasar untuk bersaing dengan brand lain.

3. Brand image dapat membantu memperbaharui penjualan suatu brand.

4. Brand image dapat dipergunakan untuk mengevaluasi efek kualitas dari strategi pemasaran.

5. Brand image dapat dihasilkan dari faktor-faktor lain di luar usaha-usaha strategi pemasaran.

Menurut (Keller, 2000) citra merek adalah persepsi konsumen terhadap citra merek produk

yang akan dikonsumsi atau dipakai. Pengukuran citra merek dapat dilakukan berdasarkan pada aspek sebuah merek, yaitu:

1. Merek mudah diingat: Artinya elemen merek yang dipilih hendaknya yang mudah diingat dan disebut atau diucapkan. Simbol, logo, nama yang digunakan hendaknya menarik, unik sehingga menarik perhatian masyarakat untuk diingat dan dikonsumsi.

2. Merek mudah dikenal: Selain dengan logo, sebuah merek dikenal melalui pesan dan cara dimana produk dikemas dan disajikan kepada para konsumen yang disebut trade dress. Melalui komunikasi yang intensif, suatu bentuk produk khusus dapat menarik perhatian dan mudah dikenali oleh konsumen. Sehingga trade dress sering sama seperti merek dagang, yaitu deferensiasi produk dan jasa di pasar yang dapat dimintakan perlindungan hukum.

3. Reputasi merek baik: Bagi perusahaan citra berarti persepsi masyarakat terhadap jati diri 
perusahaan. Persepsi ini didasarkan pada apa yang masyarakat ketahui atau kira tentang perusahaan yang bersangkutan. Perusahaan yang sama belum tentu memiliki citra yang sama pula dihadapan orang. Citra perusahaan menjadi salah satu pegangan bagi konsumen dalam memilih

Kemudian (Kartajaya, 2007) brand image di pengaruhi beberapa faktor yaitu :

1. Komunikasi dari sumber lain yang belum tentu sama dengan yang dilakukan pemasar. komunukasi bisa datang dari konsumen lain atau pengecer dan pesaing.

2. Pengalaman konsumen melalui suatu eksperimen yang dilakukan konsumen dapat mengubah persepsi yang dimiliki sebelumnya. Oleh sebab itu, junlah berbagai persepsi yang timbul itulah yang akan membentuk total image of brand (citra keseluruhan sebuah merek).

3. Pengembangan produk: posisi brand terhadap produk memang cukup unik. disatu sisi, merupakan payung bagi produk, artinya dengan dibekali brand tersebut, produk dapat naik nilainya. Di sisi lain, performa ikut membentuk brand image yang memayunginya dan tentunya konsumen.

\section{Branding Destisinasi}

Brand yang sudah melewati tahap tersebut haruslah memiliki kekuatan. Kekuatan suatu Brand Destinasi salah satunya berasal dari identitas destinasi itu sendiri. Untuk menciptakan Brand Destinasi yang kuat, dapat mengacu pada aspek-aspek kekuatan Brand Destinasi (Risitano, 2005, p. 7) berikut ini :

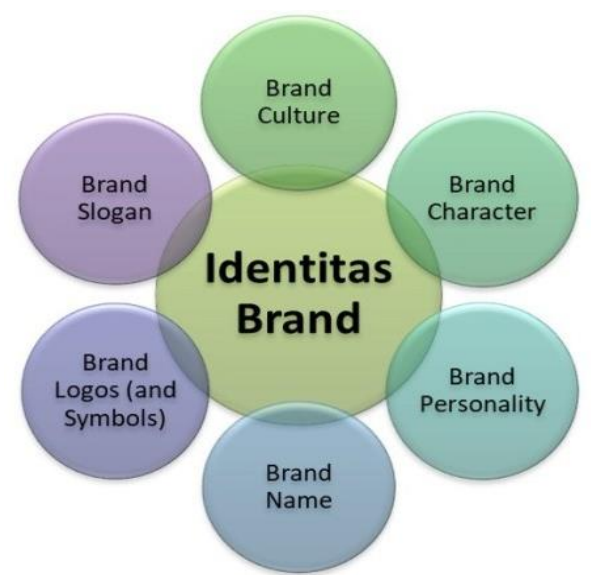

Sumber : Risitanto 2005 
Kemudian (Avraham, 2018) dalam hasil penelitiannya dalam strategi pengembangan brand beskla nasional harus mengunakan penggunaan tiga jenis strategi oleh pemasar yang terdiri dari : sumber (kesaksian pribadi, menyalahkan media), pesan (memperluas citra sempit, penggunaan selebritas) dan audiens (penekanan pada nilai-nilai yang sama, simbol budaya dan geografi, mengubah target audiens).

\section{METODE PENELITIAN}

Dalam penelitian ini metode yang digunakan penelitian "Membangun Branding Image Kepulauan Riau Sebagai Destinasi Wisata Nasional" adalah metode deskriptif kualitatif. Metode kualitatif dipakai untuk mendiskripsikan dan menerasikan data-data yang diperoleh baik data primer maupun data sekunder.

Terkait hal tersebut akan diteliti unsur pembentukan brand positioning Kepulauan Riau yang meliputi persepsi pelaku pasar wisata (wisatawan) terhadap brand destinasi wisata di Kepulauan Riau sehingga nantinya memunculkan Branding Image Wisata. Selain itu, penulis juga menggunakan tiga alur kegiatan yang terjadi secara bersamaan dalam metode kualitatif, yaitu reduksi data, penyajian data dan penarikan kesimpulan.

(Creswell, 2013) Dalam reduksi data terdapat beberapa tahap yaitu terdiri dari proses pemilihan, penyederhanaan, pengabstrakan dan transformasi data kasar yang muncul dari catatancatatan tertulis yang didapat dari kegiatan di lapangan. Reduksi data digunakan untuk menajamkan dan mengarahkan, serta membuang yang tidak perlu. Sehingga dapat ditarik kesimpulan secara tepat yang kemudian dapat diuji kebenarannya atau diverivikasi. Dari hasil yang telah diterima, penyajian hasil data akan dilakukan secara informal (dalam bentuk naratif) yaitu mengidentifikasikan potensi yang ada sehingga diperoleh suatu gambaran lengkap.

\section{HASIL DAN PEMBAHASAN}

\section{Brand Culture}

kementerian wisata memiliki target kunjungan wisata manca negara pada tahun 2019 sebesar 20 juta wisatawan. Berbagai upaya dan usaha dilakukan untuk memenuhi target tersebut. Salah satunya adalahh manajemen Branding yang berarti adalah merek. Branding sendiri adalah sebagai pembeda atapun pembanding dengan merek-merek lainnya. Kegiatan komunikasi dalam rangka proses membangun, membesarkan dan ada menguatkan yaitu brand itulah yang disebut dengan branding. Tanpa adanya kegiatan komunikasi atau publikasi tersebut maka sebuah brand atau merek tidak akan berarti apa-apa pada bagi suatu produk. Juga berlaku pada brand yang terdapat pada produk wisata yang menggambar budaya, Tradisi dan keindahan destinasi wisata.

Berdasarkan apa yang disampaikan oleh Kementerian Wisata diatas dapat disimpulkan bahwa keberadaan brand atau merek suatu destinasi melalui branding adalah penting, karena merek atau citra tersebut akan mempengaruhi persepsi wisatawan dalam motivasi untuk datang berkunjung ke destinasi tersebut. Namun saat ini branding Kepulauan Riau sebagai destinasi wisata nasional masih belum banyak yang mengenal branding yang tepat dan sesuai di bidang kewisataan. 


\section{Brand Character}

Branding wisata Kepulauan Riau dengan Wonderful Riau Islands sudah diluncurkan oleh Kementerian wisata pada tahun 2017. Branding wisata Kepulauan Riau tidak lagi Worderful Kepri. Brandingnya berubah menjadi Worderful Riau Island. Perubahan branding wisata ini terusmenerus disosialisasikan. Logo itu diganti dengan Worderful Riau Island karena akronim Kepri itu agak sulit dikenal wisatawan. "Karena itu lebih baik kita pakai logo Worderful Riau Island dan kita coba sosialisasikan logo ini.

Bahwa untuk membatinkan branding Worderful Riau Island, pemerintah daerah dan pelaku wisata harus melakukan terobosan. Misalnya, menciptakan pengalaman unik bagi wisatawan saat datang di daerah destinasi wisata. "Kita perlu menciptakan pengalaman unik saat wisatawan turun di pelabuhan dan Bandara. Selain ada logo "Worderful Kepri Island" para wisatawan juga misalkan disuguhkan tarian, pesona bahari, budaya dan event-event lainnya.

\section{Brand Personality}

Menurut Kementerian Wisata RI Bidang Destinasi Wisata. Memang kita belum harus membuat tentang branding wisata, namun sebelumnya sudah pernah ada branding sebelumnya sudah dimulai untuk membuat branding, ada beberapa terobosan yang sudah dilakukan dalam sosialisasi branding wisata Kepulauan Riau dengan Wonderfull Kepri, namun sosialisasi tersebut belum maksimal dilakukan dan bagi wisatawan mancanegara masih sulit mengucapkan Kepri, wisatawan manca negara lebih banyak mengetahui tentang Batam Islands, Bintan Islands.

Tingkat Penghunian Kamar (TPK) hotel berbintang di Provinsi Kepulauan Riau pada bulan November 2018 mencapai rata-rata 58,30 persen atau naik 0,71 poin dibanding TPK Oktober 2018 sebesar 57,59 persen. Rata-rata lama menginap tamu asing dan tamu Indonesia pada hotel berbintang di Provinsi Kepulauan Riau pada bulan November 2018 adalah 1,80 hari atau turun 0,06 poin dibanding dengan rata-rata lama menginap tamu pada. Brand Destinasi yang diciptakan perlu melewati tahap yang sulit dan panjang, dan memiliki brand personality.

\section{Brand Name}

Branding atau di sebut dengan logo memang kedepan kita perlukan karena branding tersebut dapat menambah atau mempengaruhi terhadap promosinya wisata di Kepulauan Riau. Kesepuluh destinasi dengan branding baru antara lain Bandung, Bali, Jakarta, Kepri, Joglosemar (Jogja - Solo - Semarang), Coral Wonders (Wakatobi - Bunaken - Raja Ampat), Medan, Makassar, Lombok, dan Banyuwangi.

Adapun nama-nama brand yang diluncurkan antara lain, Colorful Medan, Wonderful Riau Island, Enjoy Jakarta, Stunning Bandung, Java Cultural Wonders, Majestic Banyuwangi, Bali the Island of Gods, Friendly Lombok, Explore Makassar, serta Coral Wonders untuk Bunaken, Wakatobi, dan Raja Ampat. "Tentu Wonderful Riau Islands menjadi sesuatu yang spesial bagi Kepri. Karena bisa disejajarkan dengan Wonderful Indonesia. 
Artinya dimanakan Wonderful Riau Islands, sudah pasti membawa Wonderful Indonesia, kenapa Kepri menjadi salah satu Destinasi Branding....? karena sudah memiliki sarana dan prasarana pendukung wisata

\section{Brand Logos}

Jika diperhatikan Logo atau simbol Brand Wisata Wonderful Kepri. Bahwa logo atau simbol tersebut belum mendefinisikan kekuatan dari sebuah destinasi melalui sebuah tampilan visual, seperti keindahan alam destinasi tersebut, monumen terkenal, keunikan tradisi, dan lain-lain. Tidak hanya berupa gambar, namun jenis tulisan dan warna tulisan juga termasuk ke dalam Brand. Setelah ada perubahan logo atau simbol pada brand wisata kepri dengan tema "Wonderful Riau Islands" dapat diperhatikan dari segi visual tentang keindahan bahwa Kepri dengan wisata maritim atau keindahan alam dengan lautnya menjadi prioritas utama sebagai karakteristik branding.

\section{Brand Slogan}

Meskipun tidak selalu ada slogan dalam Brand Destinasi, nyatanya Brand Slogan yang akan di butuhkan untuk mengkomunikasikan brand secara lebih persuasif sehingga wisatawan yang asalnya tidak tertarik menjadi tertarik untuk berkunjung.

Brand memegang peranan penting dalam pemasaran destinasi wisata. Memiliki sebuah brand yang mampu merepresentasikan nilai, budaya, filosofi, harapan masyarakat atau stakeholder di dalam suatu destinasi tentunya akan sangat berpengaruh positif terhadap perkembangan wisata di destinasi tersebut. Brand slogan merupakan suatu aspek yang penting dalam sebuah branding yang mudah untuk diucapkan dan diingat.

\section{KESIMPULAN}

Berdasarkan hasil penelitian dan analisis, maka diperoleh kesimpulan sebagai berikut :

1. Merujuk pada Brand atau logo serta visi pemerintahan untuk membangun menjadikan Kepulauan Riau sebagai Destinasi Wisata nasional, diperlukan membangun national branding yang terintegrasi dalam satu konsep yang utuh, yang mengangkat atau menonjolkan tentang potensi aspek culture, character dan personality dari maritim. Branding Image tentu saja harus terintegrasi dengan branding-branding lain yang dikreasikan untuk kepentingan serupa, baik yang dilansir dan dikombinasikan dengan kota dan kabupaten, dalam hal ini Wisata dan Perdagangan. Branding, harus merujuk pada tema utama Branding Kepulauan Riau.

2. Kebijakan pemerintah dalam bidang wisata dan bidang-bidang lain terkait masih mempunyai kelemahan, yaitu: visi sebagai destinasi wisata yang dicanangkan masih belum berpijak pada kekuatan budaya lokal yang dimiliki dan mewakili aspirasi masyarakat (Liu et al., 2020). Hal ini terlihat belum konsistensi dan sinkronisasi antara kebijakan di bidang wisata dengan bidang-bidang lain sehingga potensi-potensi di bidang pendidikan, sejarah dan budaya belum terakomodasi.

3. Arah pengembangan wisata Kepri sebagai destinasi wisata di masa depan masih memprioritaskan wisata belanja dan kuliner padahal untuk Kepulauan 
4. Riau wisata budaya dan religius sangat potensial untuk dikembangkan, sedangkan untuk wilayah pesisir wisata alam dan seni tradisional mesti menjadi perhatian.

5. Pendapat wisatawan tentang industri wisata beragam, sebagian besar wisatawan menyambut dengan baik dengan keunggulan wisata belanja dan kuliner. Yang lain memandang bahwa wisata sejarah dan budaya masih belum digarap sebagai paket wisata yang menarik, selain itu para wisatawan juga mengharapkan Kepulauan Riau yang semakin aman, nyaman, bersih dan bersahabat.

Dengan memperhatikan kondisi industri wisata Kepulauan Riau saat ini, potensi yang dimiliki oleh Kepulauan Riau, serta makna dan branding wisata, Penulis mengajukan saran sebagai berikut:

1. Bidang wisata yang bisa menjadi brand image Kepulauan Riau adalah:

a. Wisata budaya yang berbasis pada budaya dan maritim yang mencakup: kesenian, peninggalan sejarah,

b. Wisata alam dengan melalukan perbaikan dalam hal diseminasi informasi, akses, dan akomodasi, terutama di tempat tujuan wisata.

2. Dalam membangun Brand Kepri sebagai destinasi wisata nasional perlu memperhatikan filosofi yaitu dasar dasar pengetahuan, dan proses yang digunakan untuk mengembangkan dan merancang pandangan mengenai suatu brand, dari segi warna, tulisan, lambang dan aspekaspek dari potensi destinasi wisata tersebut, seperti pantai, laut yang biru.

\section{DAFTAR PUSTAKA}

Aarstad, J., Ness, H., \& Haugland, S. A. (2015). Network position and tourism firms' co-branding practice. Journal of Business Research, 68(8), 1667-1677. https://doi.org/10.1016/j.jbusres.2015.03.025

Avraham, E. (2018). Nation branding and marketing strategies for combatting tourism crises and stereotypes toward destinations. Journal of Business Research. https://doi.org/10.1016/j.jbusres.2018.02.036

Bungin, B. (2015). Komunikasi pariwisata (tourism dan communication) : Pemasaran dan brand destinasi. Prena Media.

Chow, H. wen, Ling, G. J., Yen, I. yin, \& Hwang, K. P. (2017). Building brand equity through industrial tourism. Asia Pacific Management Review, 22(2), 70-79. https://doi.org/10.1016/j.apmrv.2016.09.001

Creswell, J. W. (2013). Research Design: Qualitative, Quantitative, and Mixed Methods Approaches. In SAGE Publications. 
Davis, S. M. (2002). Brand asset management: Driving profitable growth through your brands (2nd ed.). John Wiley \& Sons.

Harrigan, P., Evers, U., Miles, M., \& Daly, T. (2017). Customer engagement with tourism social media brands. Tourism Management, 59, 597-609. https://doi.org/10.1016/j.tourman.2016.09.015

Karlina, T., \& Iskandar, I. (2017). Upaya Indonesia meningkatkan jumlah kunjungan wisatawan mancanegara di Kepulauan Riau. Jurnal Online Mahasiswa Fakultas Ilmu Sosial Dan Ilmu Politik, 4(2), 1-11.

Kartajaya, H. (2007). Elemen marketing on brand. Mizan Pustaka.

Keller, K. L. (2000). The brand report card. Harvard Business Review.

Kotler, Philip., \& Armstrong, G. (2006). Principles of marketing. Prentice Hall.

Kovathanakul, D. (2015). Central Northeastern Thailand Tourism Branding, Supporting the ASEAN Economic Community. Procedia Economics and Finance, 23, 291-297. https://doi.org/10.1016/s2212-5671(15)00469-4

Liang, A. R. da, Nie, Y. Y., Chen, D. J., \& Chen, P. J. (2020). Case studies on co-branding and farm tourism: Best match between farm image and experience activities. Journal of Hospitality and Tourism Management, 42, 107-118. https://doi.org/10.1016/j.jhtm.2019.11.009

Liu, Y., Hultman, M., Eisingerich, A. B., \& Wei, X. (2020). How does brand loyalty interact with tourism destination? Exploring the effect of brand loyalty on place attachment. Annals of Tourism Research, 81. https://doi.org/10.1016/j.annals.2020.102879

Mahadiansar, \& Aspariyana. (2020). PEST analysis model dalam pengembangan potensi wisata pulau Benan Kabupaten Lingga Kepulauan Riau. Indonesian Journal of Tourism and Leisure, 1(1), 14-25. https://doi.org/10.36256/ijtl.v1i1.93

Matiza, T., \& Slabbert, E. (2020). South Africa's place brand: A marketing axiom to South Africa as a tourism destination? Journal of Destination Marketing and Management, 15. https://doi.org/10.1016/j.jdmm.2019.100380

Morgan, N., Pritchard, A., \& Pride, R. (2011). Destination brands: Managing place reputation. In Place Branding and Public Diplomacy (3rd ed., Vol. 7, Issue 4). Macmillan Publishers. https://doi.org/10.1057/pb.2011.25

Poti, J. (2016). Membangun national branding image Kepulauan Riau sebagai poros maritim dunia. Jurnal Ilmu Administrasi Negara (JUAN), 4(1), 1-13. 
Risitano, M. (2005). The role of destination branding in the tourism stakeholders system, The Campi Flegrei case. IV International Doctoral Tourism and Leisure Colloquium, $1-18$.

Santos, G. E. de O., \& Giraldi, J. de M. E. (2017). Reciprocal effect of tourist destinations on the strength of national tourism brands. Tourism Management, 61, 443-450. https://doi.org/10.1016/j.tourman.2017.03.011

Straub, J. T., \& Attner, R. F. (1994). Introduction to business (5th ed.). PWS-Kent.

Wilson, J. S., \& Blumenthal, Ira. (2008). Managing brand you : Seven steps to creating your most successful self. American Management Association 